\title{
Evaluation of ATP measurements to detect microbial ingress by wastewater and surface water in drinking water.
}

Vang, Óluva Karin; Corfitzen, Charlotte B.; Smith, Christian; Albrechtsen, Hans-Jørgen

Published in:

Water Research

Link to article, DOI:

10.1016/j.watres.2014.07.015

Publication date:

2014

Document Version

Peer reviewed version

Link back to DTU Orbit

Citation (APA):

Vang, Ó. K., Corfitzen, C. B., Smith, C., \& Albrechtsen, H-J. (2014). Evaluation of ATP measurements to detect microbial ingress by wastewater and surface water in drinking water. Water Research, 64, 309-320.

https://doi.org/10.1016/j.watres.2014.07.015

\section{General rights}

Copyright and moral rights for the publications made accessible in the public portal are retained by the authors and/or other copyright owners and it is a condition of accessing publications that users recognise and abide by the legal requirements associated with these rights.

- Users may download and print one copy of any publication from the public portal for the purpose of private study or research.

- You may not further distribute the material or use it for any profit-making activity or commercial gain

- You may freely distribute the URL identifying the publication in the public portal 
This is a post print of the published article in Water Research 64 (2014) 309-320.

The publisher's version is available at $10.1016 /$ i. watres.2014.07.015

\section{Evaluation of ATP measurements to detect microbial ingress by}

\section{wastewater and surface water in drinking water}

Óluva K. Vang ${ }^{* 1)}$, Charlotte B. Corfitzen ${ }^{1)}$, Christian Smith ${ }^{2)}$ Hans-Jørgen Albrechtsen ${ }^{1)}$

${ }^{1)}$ Department of Environmental Engineering, Technical University of Denmark, Miljoevej, Building 113,

DK-2800 Kgs. Lyngby, *okva@env.dtu.dk

${ }^{2)}$ GRUNDFOS Holding A/S, Poul Due Jensens Vej 7, DK-8850 Bjerringbro

Grafical Abstract:
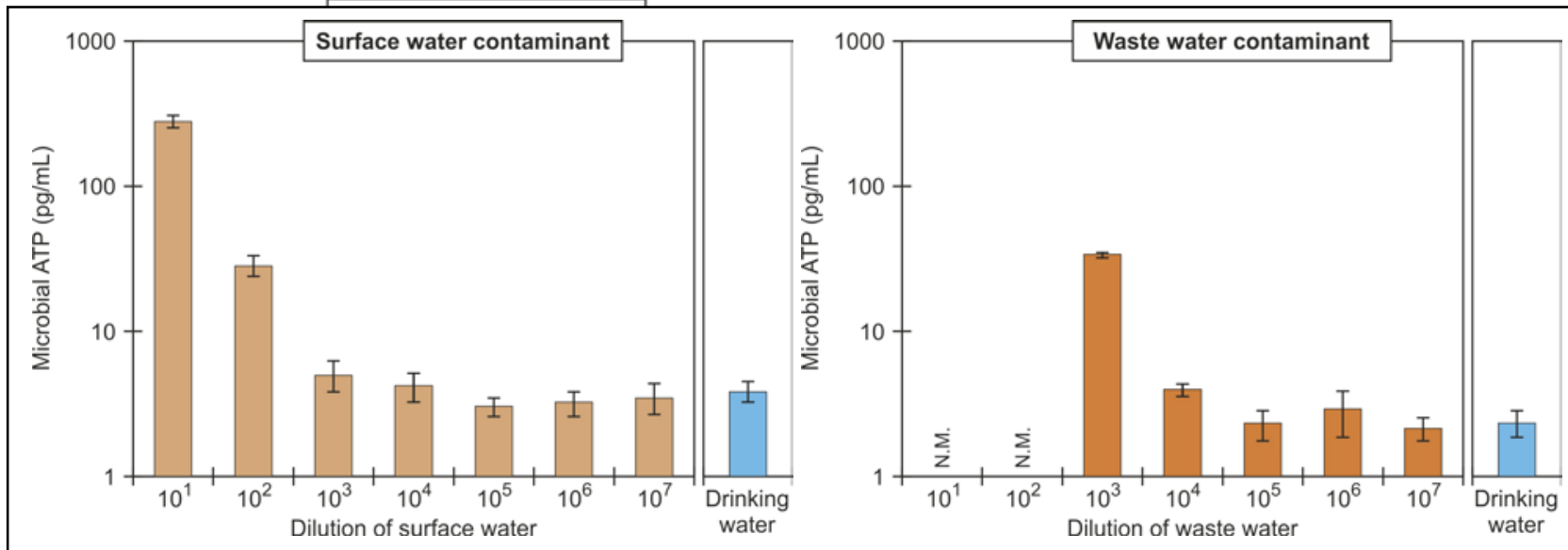

\section{Abstract}

Fast and reliable methods are required for monitoring of microbial drinking water quality in order to protect public health. Adenosine triphosphate (ATP) was investigated as a potential real-time parameter for detecting microbial ingress in drinking water contaminated with wastewater or surface water. To 
investigate the ability of the ATP assay in detecting different contamination types, the contaminant was diluted with non-chlorinated drinking water. Wastewater, diluted at $10^{4}$ in drinking water, was detected with the ATP assay, as well as $10^{2}$ to $10^{3}$ times diluted surface water. To improve the performance of the ATP assay in detecting microbial ingress in drinking water, different approaches were investigated, i.e. quantifying microbial ATP or applying reagents of different sensitivities to reduce measurement variations; however, none of these approaches contributed significantly in this respect. Compared to traditional microbiological methods, the ATP assay could detect wastewater and surface water in drinking water to a higher degree than total direct counts (TDCs), while both heterotrophic plate counts ( $\mathrm{HPC} 22^{\circ} \mathrm{C}$ and $\mathrm{HPC} 37^{\circ} \mathrm{C}$ ) and Colilert-18 (E. coli and coliforms) were more sensitive than the ATP measurements, though with much longer response times. Continuous sampling combined with ATP measurements displays definite monitoring potential for microbial drinking water quality, since microbial ingress in drinking water can be detected in real-time with ATP measurements. The ability of the ATP assay to detect microbial ingress is influenced by both the ATP load from the contaminant itself and the ATP concentration in the specific drinking water. Consequently, a low ATP concentration of the specific drinking water facilitates a better detection of a potential contamination of the water supply with the ATP assay.

Key words: adenosine triphosphate, rapid method, bacteria, drinking water, contamination 


\section{Introduction}

Nowadays microbial drinking water quality is most often monitored through grab sampling, and the current standard methods for regulatory control are usually culture-based. These traditional techniques are labour-intensive and time-consuming, and the results are usually first available 1 to 3 days after sampling. Since the residence time in distribution systems often can be relatively short, i.e. less than three days, drinking water of poor microbial quality or even contaminated with pathogenic organisms may have already been consumed when results are available. Furthermore, the low sampling frequency allows contaminations of short durations to pass undetected through the water supply system. Consequently, there is an acknowledged need for the further development of fast and reliable methods for measuring microbial drinking water quality in order to improve the protection of public health. Such rapid methods would be of value to water managers and utilities for better monitoring strategies and protection of drinking water from source to the consumer's tap.

Adenosine triphosphate (ATP) measurements provides results within minutes (Deininger and Lee, 2001; Delahaye et al., 2003; van der Wielen \& van der Kooij, 2010) and is one of several approaches (Hammes et al., 2012; Stedmon et al., 2011) which currently are being investigated as a potential parameter for evaluating the microbial quality of drinking water. Continuous sampling combined with real-time analysis such as ATP would significantly improve surveillance of microbial drinking water quality and provide an early warning system, thus allowing health authorities and managers to react in a timely manner. This is especially important for water supplies, which distribute drinking water without a disinfectant residual as in Denmark or the Netherlands (Smeets et al., 2009).

ATP is a measure for all active cells, including non-culturable cells, in a sample. Thus, the ATP measurement can provide a better estimate of the total active biomass in a drinking water sample than heterotrophic plate counts, where only a small fraction of total cells are quantified (often $<1 \%$ ) (Maki et al., 1986; Siebel et al., 2008). The ATP assay has proven to be applicable for measuring active biomass in 
various aquatic environments (Eydal and Pedersen, 2007; Aoki, 2008; Bushon et al., 2009), and ATP measurements have also been applied in determining microbial activity (bulk phase and biofilm) in drinking water systems in several investigations (Boe-Hansen et al., 2002; Delahaye et al. 2003; Lehtola et al., 2004; Hammes et al., 2010; van der Wielen \& van der Kooij, 2010; Inkinen et al., 2014). ATP measurements can be used for assessing general microbial quality in distributed drinking water (van der Wielen \& van der Kooij, 2010), although they are also applicable as a technical parameter of the efficiency of treatments processes at waterworks (Hammes et al., 2008; Vital et al., 2012; Liu et al., 2013a). Moreover, ATP measurements have also been used as a microbiological parameter for assessing regrowth in drinking water (Siebel et al., 2008; Lautenschlager et al., 2010; Vital et al., 2012; Liu et al., 2013a). ATP measurements are also used as a monitoring parameter of microbial drinking water quality in the Netherlands (van der Kooij, 2003; van der Wielen \& van der Kooij, 2010).

Water supply systems can be contaminated by, for example, wastewater or surface water with increased amounts of microorganisms and/or readily available substrates which may then lead to regrowth. It is unclear to what degree the ATP assay can detect contaminations caused by microbial ingress from wastewater or surface water, or how much of this water has to be present before ATP concentrations are increased. Earlier studies have been limited to investigations of drinking water spiked with E. coli combined with incubation of water samples (Fundzhyan \& Ugarova, 2007; Ghazali et al., 2010; Inkinen et al., 2013). However, laboratory cultures differ significantly from 'real-life' contaminants in terms of bacterial and substrate composition, bacterial abundance and other substances such as particles and chemicals.

Thus, the overall aim of this study was to investigate and interpret the response in ATP when drinking water is subjected to microbial ingress, and more specifically to assess to what degree drinking water contaminated with wastewater or surface water can be detected with the ATP assay. Other aspects investigated were 1) how ATP fractions and reagent sensitivity influence the ATP assay's ability to detect 
contaminations, 2) whether regrowth derived from a contamination can be detected and 3) how the ATP assay performs compared with traditional methods in detecting microbial ingress in drinking water.

\section{Materials and methods}

\subsection{Experimental conditions}

To investigate the response in ATP to a contamination, drinking water was contaminated with untreated wastewater or surface water at tenfold dilutions $\left(10^{1}-10^{7}\right.$ times dilution of contaminant). A volume of $100 \mathrm{~mL}$ of contaminant was diluted in $900 \mathrm{~mL}$ of drinking water ( $10^{1}$ dilution), while further dilutions of contaminant were prepared from each preceding dilution of contaminant in drinking water. Four batch experiments were carried out on four different days. Three separate experiments were performed with wastewater-contaminated drinking water in order to investigate various aspects of the contamination scenario (different ATP fractions, different ATP reagents, regrowth) as well as to evaluate the reproducibility of the ATP assay's performance. One experiment was conducted on drinking water contaminated with surface water. Groundwater-based drinking water (non-chlorinated) was collected from a local waterworks (Lyngby Vandværk), untreated wastewater from a wastewater treatment plant (Mølleåværket) and surface water from a pipe dig-out after a rainfall event - all of which were collected on the same day as the experiments were done (Table 1.).

Batch experiments were carried out to investigate the response in ATP from regrowth derived from a wastewater contamination. Glass bottles of $1 \mathrm{~L}$ drinking water contaminated with wastewater were incubated in the dark at $10^{\circ} \mathrm{C}$ under stagnant conditions. Samples were measured after 0,6 and 26 hours and after 6 days for total ATP according to method description given in section 2.2,

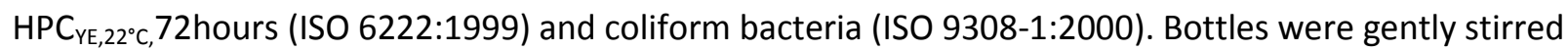
before sampling. 


\begin{tabular}{|c|c|c|c|c|}
\hline & & $\begin{array}{c}\text { Drinking } \\
\text { water }^{\mathrm{a})} \\
(\mathrm{N}=4)\end{array}$ & $\begin{array}{c}\text { Surface } \\
\text { water } \\
(\mathrm{N}=1)\end{array}$ & $\begin{array}{l}\text { Wastewater }^{\mathrm{b}) c)} \\
\qquad(\mathrm{N}=3)\end{array}$ \\
\hline pH & & 7.6 & - & 7.9 \\
\hline Oxygen & $\mathrm{mg} / \mathrm{L}$ & 8.7 & - & - \\
\hline NVOC $^{d)}$ & $\mathrm{mg} / \mathrm{L}$ & 1.9 & - & - \\
\hline Turbidity & NTU & 0.2 & - & - \\
\hline$B O D^{e)}$ & $\mathrm{mg} / \mathrm{L}$ & - & - & 260 \\
\hline $\operatorname{COD}^{f)}$ & $\mathrm{mg} / \mathrm{L}$ & - & - & 605 \\
\hline Total-N & $\mathrm{mg} / \mathrm{L}$ & - & - & 57 \\
\hline Total-P & $\mathrm{mg} / \mathrm{L}$ & - & - & 9.6 \\
\hline $\mathrm{TSS}^{\mathrm{g})}$ & $\mathrm{mg} / \mathrm{L}$ & - & - & 384 \\
\hline$T_{D C}{ }^{h)}$ & cells $/ \mathrm{mL}$ & $\begin{array}{c}1.3 \pm 0.4 \\
\times 10^{5}\end{array}$ & $\begin{array}{c}1.6 \pm 0.4 \\
\times 10^{7}\end{array}$ & $2.4 \pm 1.0 \times 10^{8}$ \\
\hline $\begin{array}{l}\text { Microbial } \\
\text { ATP }\end{array}$ & $\mathrm{pg} / \mathrm{mL}$ & $2.3-6.4$ & $\begin{array}{c}2.8 \pm 0.3 \\
\times 10^{3}\end{array}$ & $4.0 \pm 0.4 \times 10^{4}$ \\
\hline Coliforms & $\mathrm{MPN} / \mathrm{mL}$ & $<1$ & $\begin{array}{c}1.3 \\
\times 10^{4}\end{array}$ & $3.4 \times 10^{7}$ \\
\hline E. coli & $\mathrm{MPN} / \mathrm{mL}$ & $<1$ & 30 & $2.0 \times 10^{7}$ \\
\hline
\end{tabular}

\subsection{ATP assay}

ATP occurs in drinking water as a microbial ATP fraction, which is related to active and viable cells, and a free ATP fraction (total ATP = microbial ATP + free ATP) (Hammes et al., 2010). Free ATP is thought to originate from cells in the die-of phase (Stanley, 1986). Microbial ATP concentration was obtained through a two-step ATP measurement procedure. Total ATP was measured by adding an extraction reagent (cell lysis) and then a luciferin/luciferase reagent. Free ATP was measured without cell lysis by adding only the luciferin/luciferase reagent to the sample. Microbial ATP concentration was then calculated as the difference between total ATP concentration and free ATP concentration (microbial ATP $=$ total ATP - free ATP). Samples were analysed using the LuminATE reagent kit (92687, Celsis), but in one of the experiments on drinking water contaminated with wastewater (see 3.3) the RapiScreen Health reagent kit (1230839, Celsis) was used. Both reagent kits contain an extraction reagent.

To analyse the presence of ATP, a water sample $(0.1 \mathrm{~mL})$ was added manually to a cuvette and the extraction reagent was automatically added via the dispensing system on the luminometer (excluded 
when measuring free ATP). After 10 seconds of extraction the luciferin/luciferase was also added automatically, and after a 2-second delay the light emission was measured and integrated over 10 seconds. Samples were measured in two or three replicates with a luminometer (Advance Coupe, Celsis, the Netherlands).

Sample and reagent volumes for both reagent kits followed the manufacturer's recommendations. With the LuminEX/LuminATE reagent kit this was a $100 \mu \mathrm{L}$ sample, $100 \mu \mathrm{L}$ of extraction reagent and $100 \mu \mathrm{L}$ for the enzyme reagent, whereas for the RapiScreen Health reagent kit this was a $50 \mu \mathrm{L}$ sample, $200 \mu \mathrm{L}$ of extraction reagent and $100 \mu$ for the enzyme reagent. The detection limits were $1 \mathrm{pg} / \mathrm{mL}$ for total ATP and $0.7 \mathrm{pg} / \mathrm{mL}$ for free ATP with the LuminATE reagent kit, and 0.3 and $0.5 \mathrm{pg} / \mathrm{mL}$ with the RapiScreen Health reagent kit.

Luminescence was measured in relative light units (RLUs), which were converted to ATP concentrations by a calibration curve of ATP standards measured on the same day as the experiment. Two different calibration curves were made - one for total ATP and one for free ATP. ATP standards were prepared with ATP-standard salt (92638, Celsis) reconstituted in a Lumin(PM) buffer (92678, Celsis) to a concentration of $1 \times 10^{6} \mathrm{pg} \mathrm{ATP} / \mathrm{mL}$, while dilution series in the range $2.5-1,000 \mathrm{pg} \mathrm{ATP} / \mathrm{mL}$ were made in autoclaved sterile filtrated tap water (i.e. ATP free water) as a base for an ATP-standard curve. Drinking water contaminated with wastewater was measured with standard addition to account for any potential assay inhibition caused by the wastewater (section 3.1). The internal ATP standard ( $25 \mu \mathrm{L} ; 10^{4} \mathrm{pg} / \mathrm{mL}$ ) was added to a parallel sample after the extraction of microbial ATP from cells (van der Kooij et al., 2006). After a delay of 7 seconds, the enzyme reagent was added. The ATP concentration was calculated:

$$
\operatorname{ATP}_{\text {sample }}(p g \text { ATP } / m L)=\frac{R_{\text {s }} \text { sample }}{R L U_{\text {sample+IS }}-R L U_{\text {sample }}} \cdot \operatorname{ATP}_{\text {IS }}
$$

$\mathrm{RLU}_{\text {sample }}$ : the light emission from the sample

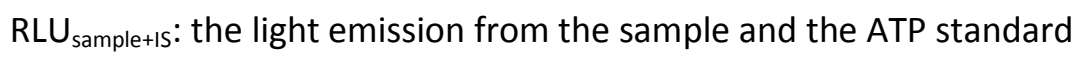


ATP $_{\text {IS: }}$ concentration of the added ATP standard

ATP sample: concentration of ATP in sample.

All glassware used for collecting water and for the experiments was acid-washed and heated to $540^{\circ} \mathrm{C}(6$ hours). ATP-free laboratory equipment and ATP-free pipette tips were applied in the experiments and all samples were handled under aseptic conditions.

\subsection{Microbial counts}

Heterotrophic plate counts (HPC) were analysed using pour plate technique on yeast extract agar (01497, Fluka Analytical, Sigma-Aldrich). A $1 \mathrm{~mL}$ water sample was transferred to a sterile petri dish and mixed with liquid yeast extract agar at $45^{\circ} \mathrm{C}$ with three replicates for each dilution. The plates were incubated in the dark at $22^{\circ} \mathrm{C}\left(\mathrm{HPC} 22^{\circ} \mathrm{C}\right)$ or at $37^{\circ} \mathrm{C}\left(\mathrm{HPC} 37^{\circ} \mathrm{C}\right)$, and the colonies were counted after $68 \pm 4$ and $44 \pm 4$ hours, respectively (DS/EN ISO 6222:1999).

Escherichia coli and coliform bacteria were measured using IDEXX Colilert ${ }^{\circledR}-18$ (ISO 9308-2:2012). The samples were incubated in trays (Quanti-Tray ${ }^{\circledR} / 2000$, IDEXX) for $20 \pm 2$ hours at $37^{\circ} \mathrm{C}$, after which yellow wells were counted and the most probable number (MPN) for coliform bacteria was determined. Under UV light, fluorescing wells were counted and used to determine the MPN of E. coli in the samples.

\subsection{Total cell count}

Samples for total cell count analyses were preserved with a buffered formaldehyde solution to a final concentration of $2 \%$ and stored at $4^{\circ} \mathrm{C}$ until analysed. The total number of microbial cells was counted after being stained with DAPI (4',6-diamidino-2-phenylindole) for five minutes in the dark (Porter \& Feig, 1980). Samples (8-38 mL) were filtrated through a black $0.22 \mu \mathrm{m}$ polycarbonate filter (GE Water \& Process Technologies, cat. no. K02BP02500), which was wetted with a $2 \%$ solution of Tween-80 in order to reduce surface tension. Subsequent to the filtration of the sample, $0.5 \mathrm{~mL}$ of a DABCO solution (1,4- 
diazabicyclo-(2,2,2)-octan) was added to the filter in order to prolong the fluorescence of the stained cells (Johnson et al., 1982), which were finally enumerated using fluorescence microscopy (Olympus BH2). We counted 400 to 1200 DAPI stained particles per subsample, where 15 or 20 different grids on the filter were counted.

\subsection{Statistics}

Linear regression analysis using the least squares method was used to determine the theoretical amount of wastewater detectable in drinking water with ATP measurements (section 3.1).

The coefficient of variation (CV) defined as the ratio of the standard deviation $(\sigma)$ to the arithmetic mean $(\mu)$ was calculated for comparison of measurement variation of different reagents for the ATP assay:

$\mathrm{CV}=\frac{\sigma}{\mu}$

Experimental data were analysed by a t-test with a significance level of 0.05 to calculate whether concentrations of bacteria measured by the different methods described above were significantly different in drinking water contaminated with wastewater or surface water as opposed to noncontaminated drinking water. Statistics were computed in Excel. Statistical calculations on a two-way ANOVA with Bonferrini post-test was made using GraphPad Prism (version 5.00, 2007) for evaluating statistical significance (section 3.4).

\section{Results and discussion}

\subsection{Drinking water contaminated with wastewater}

To investigate the ability of the ATP assay to detect contaminants in drinking water, total ATP was measured in drinking water contaminated with wastewater. Total ATP concentration in the non- 
contaminated drinking water $(3.7 \pm 0.5 \mathrm{pg}$ total $/ \mathrm{mL})$ was subtracted from total ATP measured in drinking water contaminated with wastewater (Figure 1), which demonstrated a response for all dilutions $\left(10^{1}\right.$ to $10^{5}$ ) of wastewater in drinking water.

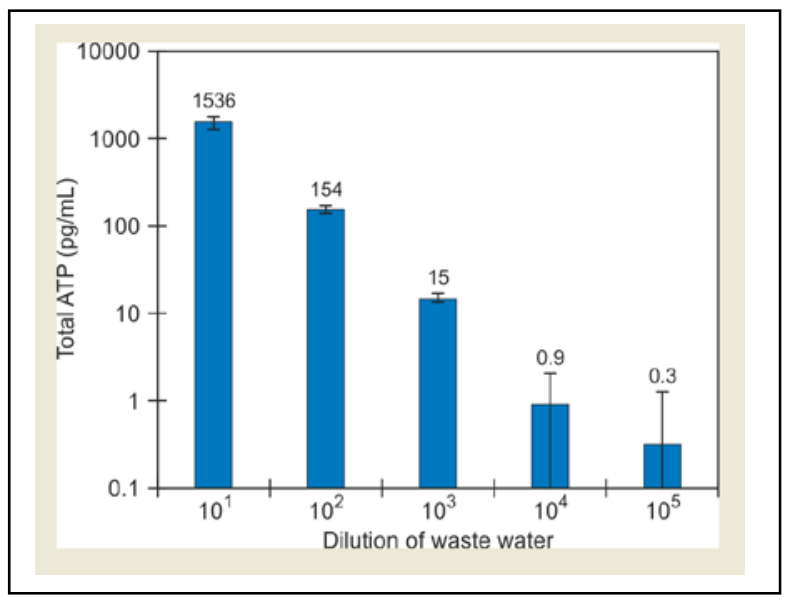

Figure 1: Total ATP concentrations (artithmetic mean with standard deviation given with error bars, $\mathrm{N}=2$ ) in drinking water contaminated with wastewater. Background level of ATP (i.e. drinking water) is subtracted from samples contaminated with wastewater of various dilutions (LuminATE reagent kit).

Total ATP concentrations decreased tenfold for each tenfold dilution of wastewater for the three lowest dilutions $\left(10^{1}, 10^{2}\right.$ and $\left.10^{3}\right)$, therefore showing linearity for these dilutions. Total ATP concentration in the $10^{3}$ dilution $(18.7 \pm 1.5 \mathrm{pg}$ total ATP $/ \mathrm{mL})$ was significantly higher than in drinking water $(3.7 \pm 0.5 \mathrm{pg}$ total ATP/mL) $(p<0.05, N=2)$. The signal for the two most diluted wastewater samples was higher than in drinking water -0.9 and $0.3 \mathrm{pg} / \mathrm{mL}$ in the $10^{4}$ and $10^{5}$ dilution of wastewater respectively - although the difference was not statistically significant $(p>0.05, N=2)$. Hence, the ability of the ATP assay to detect wastewater contamination in this specific experimental set-up was between a $10^{3}$ and a $10^{4}$ dilution of wastewater - equivalent to $0.1-1 \mathrm{~L}$ in $1 \mathrm{~m}^{3}$.

Through linear regression analysis of total ATP concentrations $\left(N=5, R^{2}=1.0, p<0.0001\right)$ the theoretical amount of wastewater detectable in drinking water was a $1.2 \times 10^{5}$ dilution of wastewater $(\mathrm{x}=\mathrm{b} / \mathrm{a}$; $a=15363 \pm 4 ; b=0.18 \pm 0.2$ ). ATP concentrations in the low dilutions were several orders of magnitude 
higher than in the high dilutions and as such had a relatively greater influence on the regression analysis, which in this specific case led to an overestimation of the ability of the ATP assay.

The bioluminescent reaction of ATP and luciferin/luciferase can be inhibited by, for example, luciferin analogues, nucleotides and a variety of anions and cations, some to a lesser extent than others (Denburg et al., 1969; Deluca et al., 1979; Karl, 1980). Samples were measured with standard addition to account for these potential matrix effects and potential inhibition by substances in the wastewater. The results demonstrated a reduction in light emission of $18 \%$ and $10 \%$ for the $10^{1}$ and $10^{2}$ dilutions of wastewater in drinking water (Figure 1). However, at such high concentrations of wastewater the response in ATP is expected to be substantially higher than for clean drinking water, leaving no doubt that water quality has been compromised. Significant matrix effects or inhibition were not observed in either the clean or contaminated drinking water with wastewater diluted to $10^{3}$ to $10^{5}$, i.e. $2-8 \%$. Reduced light emission due to matrix effects and/or inhibition is accounted for ATP concentrations illustrated in Figure 1. To improve the efficiency of the ATP assay it seemed obvious to try to reduce measurement variations by either quantifying the microbial ATP fraction, and thus eliminate possible noise from free ATP, or by applying more sensitive reagents for the ATP analysis in order to better distinguish between ATP in drinking water and increased ATP levels caused by microbial ingress.

\subsection{Significance of microbial ATP on method efficiency}

Often total ATP is used as a parameter for microbial activity (van der Wielen \& van der Kooij, 2010; Liu et al., 2013a). However, drinking water may contain significant amounts of free ATP (Hammes et al., 2010; Vital et al., 2012). In our earlier studies we have shown that free ATP may constitute a significant part (5-100\%) of the total ATP concentration in non-chlorinated drinking water (Vang et al., 2014a). The presence of free ATP and the varying size of this fraction may create substantial 'noise' when total ATP is measured, i.e. free ATP might influence to which degree a contamination is detected if total ATP is 
measured, and consequently influence the efficiency of the ATP assay to detect contaminations in drinking water.

For potential improvement of the ATP assay's sensitivity, both total ATP and free ATP were measured to quantify the microbial ATP fraction (Figure 2A).

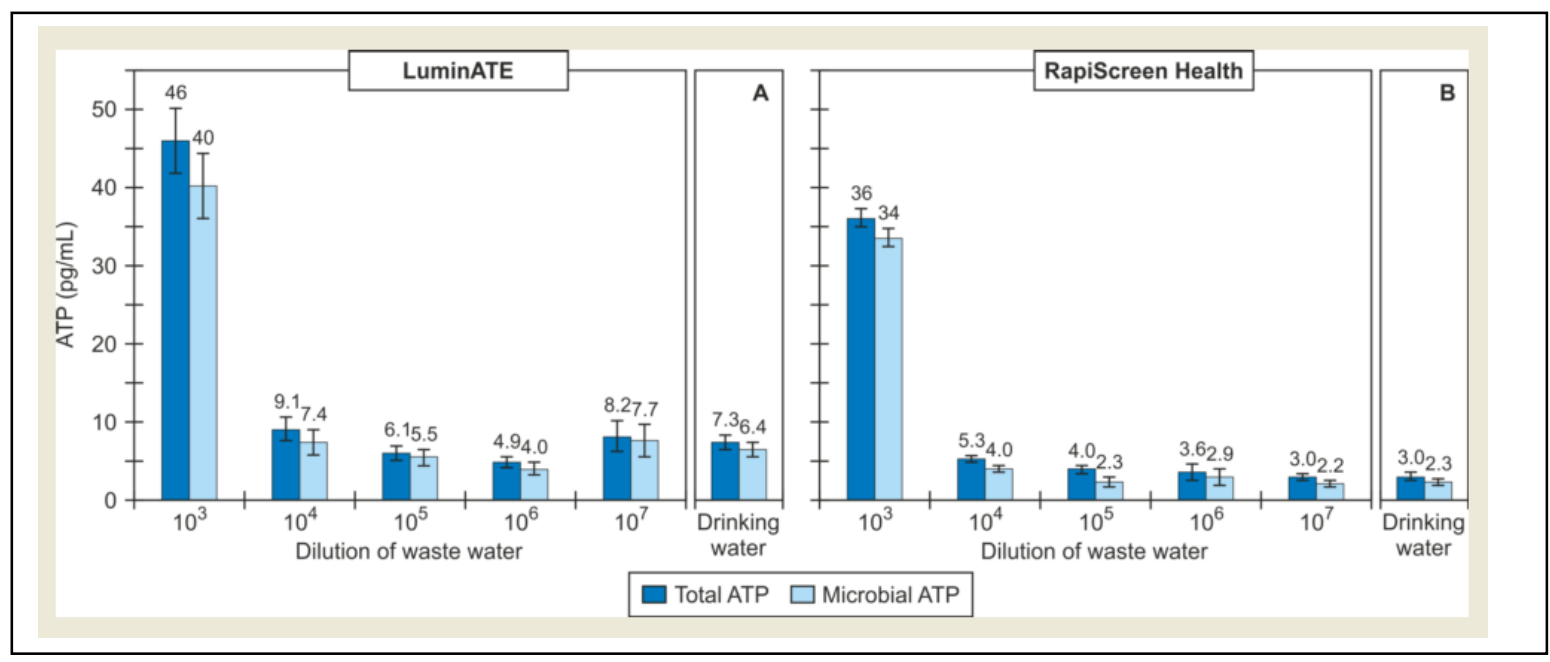

Figure 2: Total and microbial ATP concentrations (artithmetic mean with standard deviation given with error bars, $\mathrm{N}=2$ or 3 ) in drinking water and drinking water contaminated with wastewater of various dilutions; A) LuminATE reagent kit was applied for ATP measurements and B) RapiScreen Health reagent kit was applied for ATP measurements.

The concentration of the $10^{3}$ dilution of wastewater ( $40 \pm 4 \mathrm{pg}$ microbial ATP $/ \mathrm{mL}$ ) was significantly higher than in drinking water $(6.4 \pm 0.9 \mathrm{pg}$ microbial $\mathrm{ATP} / \mathrm{mL})(\mathrm{p}<0.05)$, but not for further dilutions $\left(10^{4}\right.$ to $\left.10^{7}\right)$. Free ATP concentration in the $10^{3}$ wastewater dilution was also significantly different from free ATP in drinking water, demonstrating that the wastewater contamination contributed to increased levels of both microbial and free ATP. However, the ratio between total ATP in the $10^{3}$ dilution of wastewater in drinking water and uncontaminated drinking water compared to the ratio between microbial ATP concentrations for the same sample was 6.3 in both cases. Hence, in this case quantifying microbial ATP did not improve the ability of the ATP assay to detect wastewater compared to measuring total ATP. 
ATP concentrations were different in drinking water samples collected on different days, i.e. $7.3 \mathrm{pg}$ total ATP/mL (Figure 2A) compared to $3.7 \mathrm{pg}$ total ATP/mL (see section 3.1). This is within expected natural variations in ATP concentrations in drinking water (Vang et al., 2014a; van der Kooij, 1992; Berney et al. 2008; Hammes et al., 2010; Liu et al., 2013a). However, the level of ATP in drinking water, i.e. indigenous bacteria, influences the limit for detecting microbial ingress and as such the efficiency of the ATP assay.

\subsection{Significance of reagent sensitivity on method efficiency}

ATP measurements with good repeatability might improve the differentiation between contaminated water and drinking water, and thus contribute to the ATP assay's ability to detect microbial ingress. One approach to lowering measurement variation could be to apply more sensitive reagents for the ATP analysis, i.e. an increased signal with a better signal/noise ratio. Sensitivity varies significantly between various commercial luciferin/luciferase reagents, resulting in large differences in RLU response; also some reagents are more suitable for measuring samples with low levels of ATP, as is the case for drinking water (Marriott et al., 1992; Vang et al., 2014b). The RapiScreen Health reagent is more sensitive than the LuminATE reagent, i.e. more sensitive means more light is produced per ATP molecule present in the sample, and consequently a higher yield of relative light units (RLUs) is registered by the photomultiplier without acquiring a higher background signal. The coefficient of variation (CV) for both reagents was lowest in the less diluted wastewater $\left(10^{3}\right)$ (Table 2$)$, where ATP concentrations were relatively high - CV was lower for the RapiScreen Health reagent ( $\mathrm{CV}=3 \%$ ) compared to LuminATE (CV=10\%).

Table 2: Coefficient of variation (CV) of total and microbial ATP concentrations in drinking water and drinking water contaminated with wastewater of various dilutions measured with LuminATE or RapiScreen Health reagent kit.

\begin{tabular}{|c|c|c|c|c|}
\hline \multirow{4}{*}{$\begin{array}{c}\text { Dilution of } \\
\text { wastewater } \\
10^{3}\end{array}$} & \multicolumn{2}{|c|}{$\begin{array}{c}\text { CV } \\
\text { LuminATE }\end{array}$} & \multicolumn{2}{|c|}{$\begin{array}{c}\text { CV } \\
\text { RapiScreen Health }\end{array}$} \\
\hline & Total ATP & Microbial ATP & Total ATP & Microbial ATP \\
\hline & $\%$ & $\%$ & $\%$ & $\%$ \\
\hline & 9 & 10 & 3 & 3 \\
\hline $10^{4}$ & 17 & 21 & 8 & 11 \\
\hline $10^{5}$ & 16 & 18 & 14 & 24 \\
\hline $10^{6}$ & 15 & 23 & 28 & 35 \\
\hline $10^{7}$ & 24 & 27 & 13 & 19 \\
\hline Drinking water & 13 & 15 & 16 & 21 \\
\hline
\end{tabular}


The CV was also lower for the $10^{4}$ dilution of wastewater when measured with RapiScreen Health than with LuminATE. Hence, measurement variation is reduced with the sensitive RapiScreen Health reagent at relatively high ATP concentrations, though not for low ATP levels in clean drinking water.

When ATP was measured with the RapiScreen Health reagent (Figure 2B) the $10^{3}$ dilution of wastewater in drinking water (33.6 $\pm 1.2 \mathrm{pg}$ microbial ATP $/ \mathrm{mL}$ ) was easily distinguished from drinking water. Also, microbial ATP concentration in the $10^{4}$ dilution of wastewater $(4.0 \pm 0.4 \mathrm{pg}$ microbial ATP $/ \mathrm{mL})$ was significantly higher than in drinking water $(2.3 \pm 0.5 \mathrm{pg}$ microbial ATP $/ \mathrm{mL})(\mathrm{p}<0.05, \mathrm{~N}=2)$. At higher dilutions $\left(10^{5}, 10^{6}, 10^{7}\right)$ the wastewater contamination was diluted to the ATP level exhibited by indigenous bacteria in the specific drinking water. Thus, the ability of the ATP assay to detect wastewater in this experiment was improved to detect a $10^{4}$ dilution of wastewater - equivalent to 100 $\mathrm{mL}$ in $1 \mathrm{~m}^{3}$ of drinking water. However, although not statistically significant, ATP concentration in the $10^{4}$ wastewater dilution was higher than in drinking water for all three experiments where drinking water was contaminated with wastewater, indicating a tendency to detect up to a $10^{4}$ dilution in this respect (Figure 1, Figure 2A and Figure 2B). Applying more sensitive reagents for the ATP analysis in this case did not substantially improve repeatability of replicates for samples with low ATP concentrations, i.e. in the drinking water range, and consequently did not improve the ability of the ATP assay to detect contaminants significantly.

Another aspect in evaluating the detection of contaminants with the ATP assay is the ATP concentration in wastewater, which was lower (34 pg microbial ATP/mL) in the study with the RapiScreen Health reagent (Figure $2 B$ ) than in the experiment with the LuminATE reagent (40 pg microbial ATP/mL) (Figure 2A). An increase in ATP load from the wastewater contaminant was not why a $10^{4}$ dilution of wastewater was distinguished with the RapiScreen Health reagent. On the other hand, the microbial ATP concentration in drinking water varied between the two experiments where it was relatively low (2.3 microbial $\mathrm{pg} / \mathrm{mL}$ ) in the experiment measured with the RapiScreenHealth reagent (Figure 2B) compared 
to the experiment measured with the LuminATE reagent (6.4 pg microbial ATP/mL) (Figure $2 \mathrm{~A}$ ). The ratio of ATP between drinking water contaminated with wastewater and clean drinking water was highest with the RapiScreen Health reagent kit (14.4), thus demonstrating the importance of a low ATP concentration in drinking water. This contributes to the ability of the ATP assay with regard uncovering the $10^{4}$ dilution of in this specific experiment compared to previous experiments, and not the sensitivity of the reagent applied. As such, both the microbiological load of contaminant and the ATP concentration of indigenous bacteria in drinking water are two important controlling factors in the ATP assay's ability to detect potential contaminants in drinking water.

\subsection{Detection of regrowth}

The detection of regrowth was investigated by examining drinking water contaminated with wastewater incubated at a typical drinking water temperature $\left(10^{\circ} \mathrm{C}\right)$. The contamination of a drinking water system will most likely, besides bacteria, also add substrate to the system, which can cause regrowth. The ATP levels in all dilutions $\left(10^{1}\right.$ to $\left.10^{5}\right)$ of wastewater remained more or less unaltered after 6 and 26 hours incubation. There was no increase of ATP in drinking water within 6 days of incubation, while ATP concentrations in all dilutions of wastewater - except the $10^{3}$ dilution - had increased compared to ATP concentrations measured at 0 hours (Figure 3). However, based on a two-way ANOVA with Bonferroni post-test the increase in ATP concentration was only significant for the $10^{1}$ dilution of wastewater $(p<0.001)$ (Figure 3). The ATP concentration was $20 \%$ was higher in the $10^{1}$ dilution of wastewater after 6 days incubation, $26 \%$ for $10^{2}$ dilution, $61 \%$ for $10^{4}$ dilution and $116 \%$ for $10^{5}$ dilution of wastewater. 


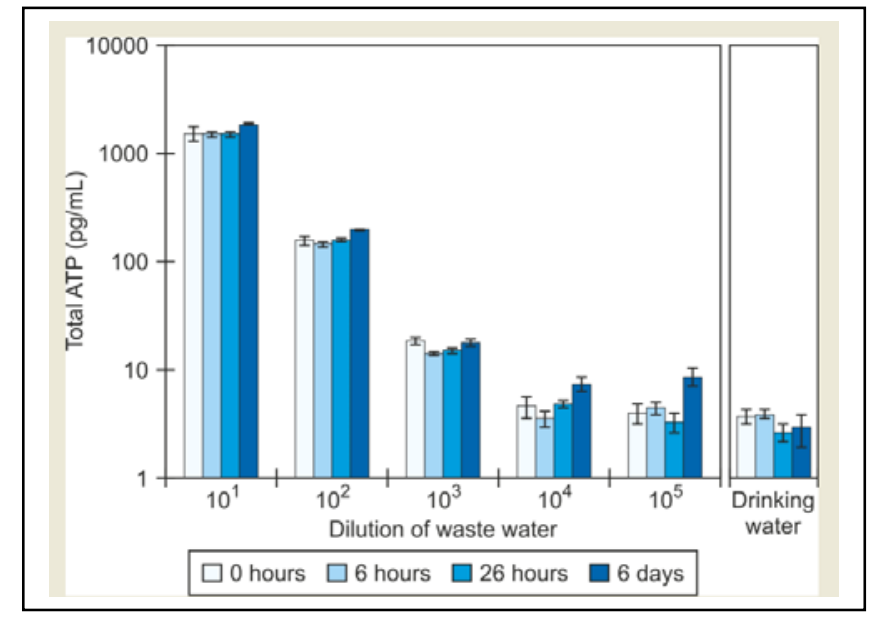

Figure 3: Total ATP concentrations (artithmetic mean with standard deviation given with error bars, $\mathrm{N}=2$ ) in drinking water and drinking water contaminated with wastewater of various dilutions measured at 0,6 and 26 hours and six days of incubation at $10^{\circ} \mathrm{C}$.

This is presumably due to regrowth of the oligotrophic drinking water bacteria at low levels of biodegradable dissolved organic carbon (BDOC) added from the wastewater contamination (BDOC was not measured in this study). Based on ATP per cell calculations $\left(2.7 \times 10^{-17} \mathrm{~g}\right.$ ATP/cell), a regrowth of 5 $\mathrm{pg} / \mathrm{mL}$, which was observed for the $10^{5}$ dilution of wastewater in day 6 , corresponds to an increase of approximately $2 \times 10^{5}$ cells. Whether or not the ATP assay is sensitive enough to detect such changes depends on the background level of ATP in drinking water. A few studies comparing flow cytometry (FCM) and ATP measurements have reported stable ATP concentrations, despite increased cell numbers with FCM, indicating that ATP measurements alone might not be suited to evaluate regrowth in drinking water (Vital et al., 2012; Liu et al., 2013a).HPC $22^{\circ} \mathrm{C}$ measurements also demonstrated significant regrowth after just 6 hours incubation for the $10^{3}$ wastewater dilution. After 26 hours of incubation all contaminant dilutions demonstrated significant regrowth in $\mathrm{HPC} 22^{\circ} \mathrm{C}$ (data not shown). Often HPC's do not correlate with ATP or TDC (Siebel et al., 2008; Hammes et al., 2010).

For a real-life distribution network contamination with continuous flow and consumption, the signal from regrowth caused by this event will most likely be diluted to the specific level of ATP in drinking water, since the increase in ATP was delayed for several days from the point and time of entry. On the other hand, in real life contaminated water might remain stagnant in pipes over several days, allowing 
regrowth of bacteria as a result of additional substrate from wastewater contamination, which in turn might cause recontamination of the network when hydraulic conditions allow.

\subsection{Drinking water contaminated with surface water}

In order to investigate other contaminant types, ATP was measured in drinking water contaminated with surface water (Figure 4). ATP concentrations decreased approximately tenfold for each tenfold dilution for the $10^{1}$ to $10^{2}$ surface water dilutions, but not at higher dilutions, since the microbial load of the surface water contaminant was diluted to the background level of ATP relevant to the specific drinking water. Microbial ATP concentrations were significantly higher in the $10^{1}$ dilution (282 pg ATP/mL) and the $10^{2}$ dilution (28 pg ATP/mL) compared to clean drinking water $(3.9 \mathrm{pg} \mathrm{ATP} / \mathrm{mL})(\mathrm{p}<0.05, \mathrm{~N}=2)$.

Microbial ATP concentrations in the $10^{3}$ and $10^{4}$ dilutions were higher than in drinking water, though the difference was not significant $(p>0.05, N=2)$. ATP concentrations in diluted surface water of $10^{5}, 10^{6}$ and $10^{7}$ were equivalent to ATP concentration in drinking water (Figure 4).

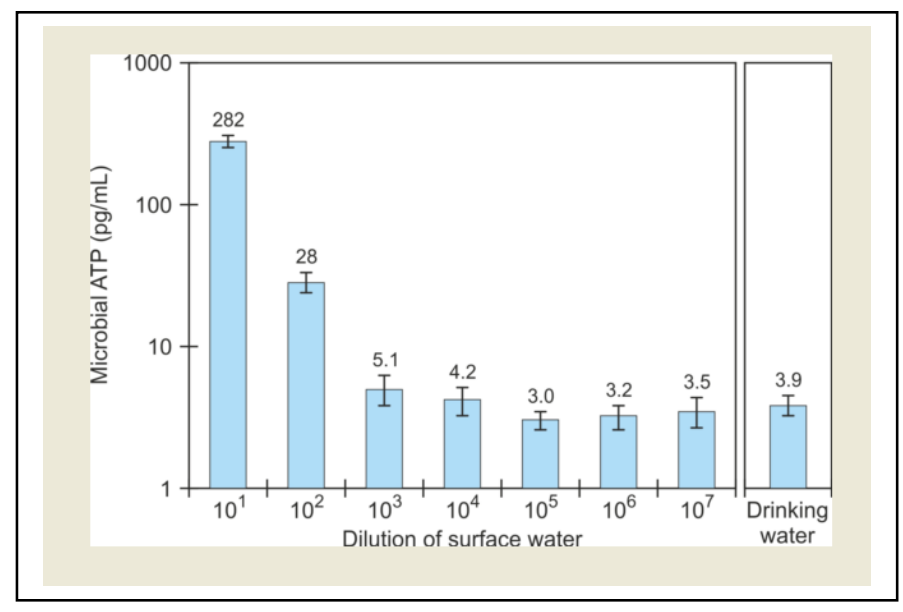

Figure 4: Microbial ATP concentrations (artithmetic mean with standard deviation given with error bars, $\mathrm{N}=3$ ) in drinking water and drinking water contaminated with surface water of various dilutions (LuminATE reagent kit).

Microbiological load will vary depending on the type of contaminant, where wastewater was detected at higher dilutions than surface water. High ATP loads from contaminants and, for example, pulse contaminations will be detected. Recently, there have been two extensive contaminations in Finland 
and Denmark, where treated wastewater $-450 \mathrm{~m}^{3}$ and $27 \mathrm{~m}^{3}$ respectively - entered the drinking water supply system (Rimhanen-Finne et al., 2010; Vestergaard et al., 2007). In these cases an ATP monitoring program would most likely detect elevated ATP levels. However, a continuous contamination with a low microbiological load will most likely not be detected with ATP measurements.

In this study only ATP was investigated for rapid detection of contaminants in drinking water. However, there are also other rapid methods for monitoring (microbial) changes in drinking water - both specific (e.g. fluorescence in situ hybridization - FISH, quantitative polymerase chain reaction - qPCR) and nonspecific methods (e.g. flow cytometry - FCM, organic matter fluorescence) (Hügler et al., 2012; Lutz et al, 2010; Vital et al., 2012; Stedmon et al., 2011). FISH and qPCR are relatively complex methods for rapid in-situ monitoring of microbial drinking water quality. Laboratory studies on organic matter fluorescence proved applicable for rapid detection of $2 \%$ wastewater in drinking water (Stedmon et al., 2011). Especially, FCM has demonstrated promising results in assessing microbial drinking water quality (Vital et al., 2012). Recently, preliminary investigations with a fully automated flow cytometer have demonstrated potential for rapid monitoring of microbial drinking water quality (Hammes et al., 2012; Nevel et al., 2013).

Another key parameter influencing the ability of the ATP assay to detect contaminations is the level of ATP in the specific drinking water, which may vary depending on type of water, treatment steps at the waterworks (Hammes et al., 2008) and time and potential spatial variations (van der Wielen \& van der Kooij, 2010). The ability to detect contaminations with ATP measurements is somewhat lower than the results of current laboratory investigations, where the precise ATP concentration in non-contaminated drinking water is known. Due to the natural variations of ATP in drinking water (van der Kooij, 1992; van der Kooij, 2003; van der Wielen \& van der Kooij, 2010; Hammes et al., 2010; Liu et al., 2013a) it is important to identify a baseline in this respect for the specific water supply system. Microbial ATP concentrations in Danish non-chlorinated drinking water (waterworks and distribution networks) have 
been reported being $<5 \mathrm{pg} / \mathrm{mL}$ in $75 \%$ of the samples (Vang et al., 2014a). Continuous online monitoring with ATP measurements would establish a baseline and provide information on potential changes in ATP throughout a day, for example, and as such it would be more efficient than grab sampling at identifying sudden increases in ATP triggered by possible contaminants.

\subsection{ATP versus traditional microbiological methods}

\section{Total direct cell counts}

Total direct cell counts (TDC) detected a $10^{3}$ dilution of wastewater $\left(2.40 \times 10^{5}\right.$ cells $\left./ \mathrm{mL}\right)$ and up to a $10^{2}$ dilution of surface water $\left(1.62 \times 10^{5}\right.$ cells $\left./ \mathrm{mL}\right)$, i.e. concentrations were significantly higher than in drinking water $\left(1.17 \times 10^{5}-1.23 \times 10^{5}\right.$ cells $\left./ \mathrm{mL}\right)(\mathrm{p}<0.05)$ (Figure 5). TDC and ATP concentrations have been found to correlate significantly in several investigations (Eydal \& Pedersen, 2007; van der Wielen \& van der Kooij, 2010).

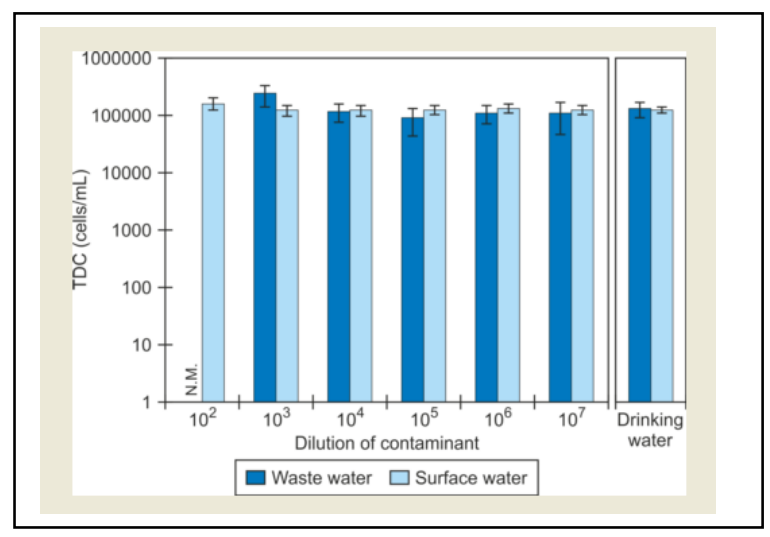

Figure 5: Total direct cell counts in drinking water and drinking water contaminated with surface water or wastewater of various dilutions (N.M.: not measured). The corresponding ATP results for surface water and wastewater are presented in Figure 4 and Figure $2 \mathrm{~A}$, respectively.

However, it is important to mention that microbial ATP is a measure for active biomass, while TDC is the total number of bacteria in a sample, i.e. living and dead bacteria. In this study, the ratio between concentrations in the $10^{2}$ dilution of surface water and drinking water was 1.3 for TDC and 7.3 for microbial ATP, while the ratio for the $10^{3}$ dilution of wastewater and drinking water was 1.8 for TDC and 
4.9, 6.3 and 14.4 for microbial ATP (based on the three different experiments). Thus, the ATP assay was better than TDC in differentiating between clean drinking water and the two types of contaminants in drinking water, since the ratio between concentrations in contaminated drinking water and clean drinking water was considerably greater for ATP than for TDC. The sensitivity of TDC might be improved by increasing the precision of the method by increasing the number of grids being counted on the filter and the concentration of cells on each grid, since the CV of TDC was 36-55\% for drinking water samples contaminated with wastewater and $17-22 \%$ for surface water contamination. Also, bacterial numbers may have been underestimated with TDC, due to multiple cells per particle (Camper et al., 1986; Liu et al., 2013b). This also demonstrates the advantage of the ATP assay compared to TDC, since ATP from bacteria in the bulk phase and particle-associated bacteria is expected to be extracted and measured. Based on the measured data, the ATP content per cell was calculated at $3.5 \pm 0.6$ and $5.6 \pm 1.8 \times 10^{-17} \mathrm{~g}$ ATP/cell. This is in the same order of magnitude as reported by others for drinking water bacteria (Magic-Knezev and van der Kooij, 2004; Velten et al., 2007; Berney et al., 2008; Hammes et al., 2008; Siebel et al., 2008; van der Wielen \& van der Kooij, 2010; Vital et al., 2012).

\section{Heterotrophic plate counts}

HPC $22^{\circ} \mathrm{C}$ decreased exponentially from the $10^{2}$ to the $10^{5}$ dilutions of surface water in drinking water (Figure $6 \mathrm{~A})$, and the $10^{4}$ dilution $\left(156 \mathrm{CFU} / \mathrm{mL}\right.$ ) was significantly higher than the $\mathrm{HPC} 22^{\circ} \mathrm{C}$ in drinking water $(16 \mathrm{CFU} / \mathrm{mL})(\mathrm{p}<0.05, \mathrm{~N}=2)$. For $\mathrm{HPC} 37^{\circ} \mathrm{C}$ the $10^{3}$ dilution of surface water $(6 \mathrm{CFU} / \mathrm{mL})$ was significantly higher than in drinking water $(1 \mathrm{CFU} / \mathrm{mL})(\mathrm{p}<0.05, \mathrm{~N}=2)$. Thus, surface water contamination was detected up to a $10^{4}$ dilution for HPC $22^{\circ} \mathrm{C}$ and up to a $10^{3}$ dilution for HPC $37^{\circ} \mathrm{C}$. For the wastewater contaminant, $\mathrm{HPC} 22^{\circ} \mathrm{C}$ was significantly higher than for drinking water at the $10^{7}$ dilution of wastewater and $\mathrm{HPC} 37^{\circ} \mathrm{C}$ at the $10^{6}$ dilution ( $p<0.05$ ) (Figure $6 \mathrm{~B}$ ), i.e. the HPC method was able to detect a 100 to 1000 times higher dilution of wastewater than the ATP assay. 


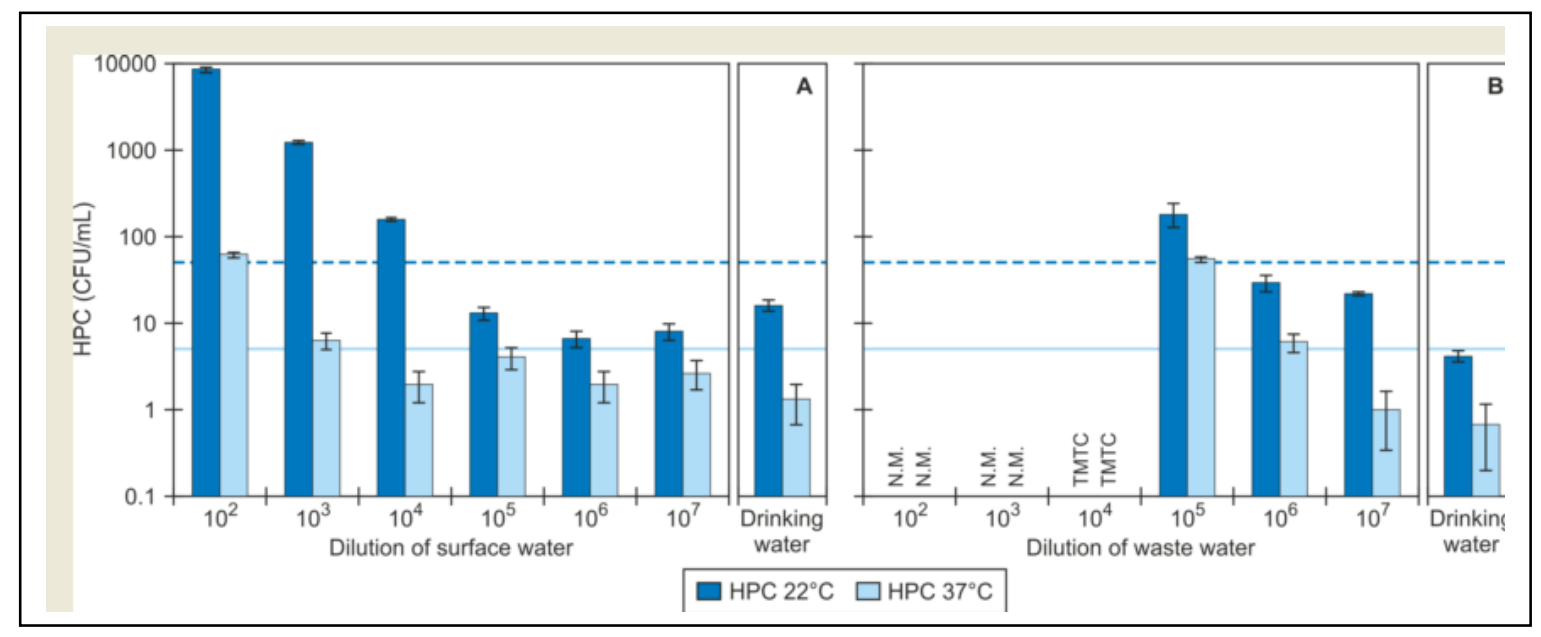

Figure 6: Concentration of heterotrophic plate counts (HPC $22^{\circ} \mathrm{C}$ and HPC $37^{\circ} \mathrm{C}-\mathrm{DS} / \mathrm{EN}$ ISO 6222:1999) in drinking water and drinking water contaminated with (A) surface water of various dilutions or (B) wastewater of various dilutions. Dotted line and full line indicate threshold values for $\mathrm{HPC} 22^{\circ} \mathrm{C}(50 \mathrm{CFU} / \mathrm{mL})$ and $\mathrm{HPC} 37^{\circ} \mathrm{C}(5 \mathrm{CFU} / \mathrm{mL})$ in finished drinking water, respectively (Danish executive order on drinking water, 2011). N.M.: not measured; TMTC: too many to count. The corresponding ATP results for surface water and wastewater are presented in Figure 4 and Figure 2A, respectively.

Consequently, the HPC method in this case was more efficient than the ATP assay in identifying both wastewater and surface water contamination in drinking water. However, HPC measurements are influenced by cultivation media, incubation temperature and culturability of the indigenous bacteria in drinking water (Reasoner \& Geldreich, 1985). Also, the presence viable-but-not-cuturable (VBNC) bacteria makes the HPC method erroneous (Maki et al., 1986). Finally, it is a time consuming method and results are not available until 2 to 3 days after sampling. All of the above explains why HPC is not at suitable method for detection of contaminations.

\section{E. coli and coliform bacteria}

E. coli (30 MPN/100 mL) was measured in undiluted surface water, while it was $<1 \mathrm{MPN} / 100 \mathrm{~mL}$ in all the surface water dilutions $\left(10^{1}-10^{7}\right)$ in drinking water (Figure $\left.7 \mathrm{~A}\right)$. Conversely, coliforms were detected in the $10^{4}$ dilution $(2.0 \mathrm{MPN} / 100 \mathrm{~mL}$ ). Hence, E. coli counts were low in the surface water contamination, 
while the coliform bacteria parameter performed equally to HPC $22^{\circ}$, i.e. these were above guideline values for the $10^{4}$ dilution of surface water.

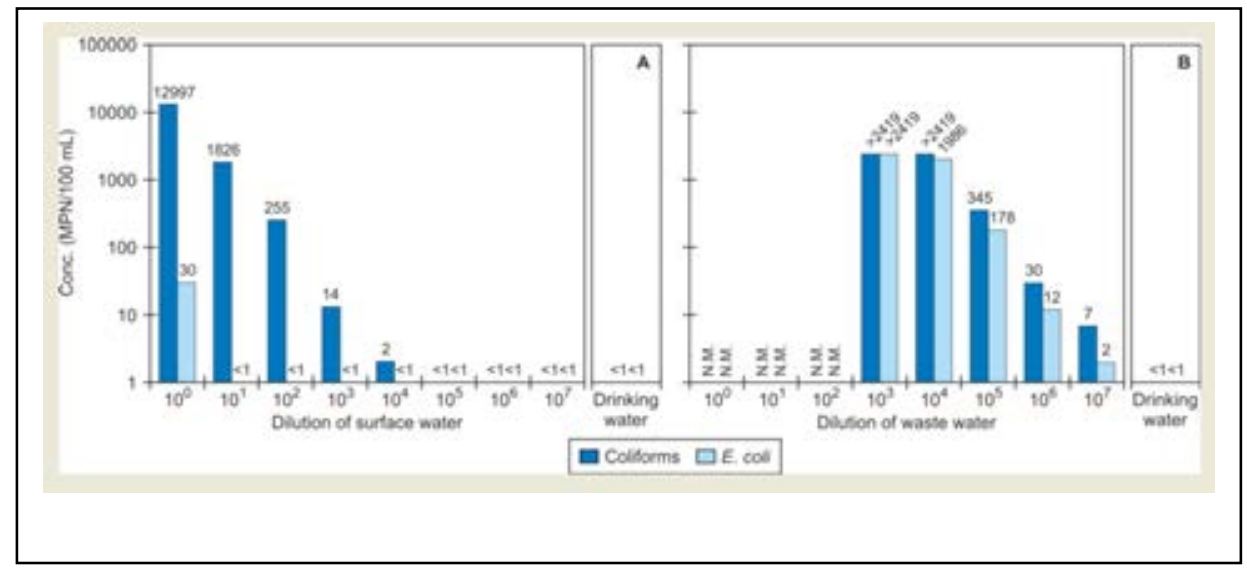

Figure 7: Concentrations of coliforms and E. coli (Coliert-18) in drinking water and drinking water contaminated with (A) surface water of various dilutions or (B) with wastewater of various dilutions. The corresponding ATP results for surface water and wastewater are presented in Figure 4 and Figure $2 \mathrm{~A}$, respectively.

For the wastewater contaminant, coliforms (7 MPN/100 mL) and E. coli (2 MPN/100 mL) were detected in the $10^{7}$ dilution of wastewater in drinking water (Figure 7B). Thus, measuring E. coli and coliforms surpassed the ATP assay and other traditional microbiological methods applied in this study in detecting the wastewater contaminant. Hence, potential pathogenic organisms may be present in drinking water without observing increased ATP concentrations. The results demonstrated that both E. coli and coliform bacteria perform very well as indicators, especially for the wastewater.

\section{Evaluation of the ATP method performance}

The different methods provide information on various microbiological characteristics and give supporting information on the microbiological state of drinking water. The methods have different pros and cons regarding response time, indicators vs. total bacteria, total counts vs. metabolically active cells vs. viable but non-culturable cells as well as different workload. 
The reproducibility of results through repeated experiments with wastewater and by also comparing different contaminants proves that ATP can be an efficient and robust parameter for assessing microbial drinking water quality. Nevertheless, despite the ability of the ATP assay to detect various types of microbial ingress in drinking water, the methodology also has its limitations. The ATP assay is a nonspecific method and represents the activity of all bacteria present in a sample. The results of this study have demonstrated that indicator bacteria (E. coli, coliforms) and thus also potentially pathogenic microbes may be present without eliciting a response in ATP, since these are present in relatively low numbers compared to the total number of bacteria. Oppositely, an increase in ATP might not always be caused by a contamination. Bacteria are often associated with surfaces, e.g. loose deposits and pipe walls as biofilm (Liu et al., 2013c). Hence, a resuspension of sediments in water pipes or detachment of biofilm can lead to increased bacterial numbers in the bulk phase, and consequently also an increase in ATP. Despite ATP being considered a robust monitoring parameter for microbial drinking water quality, in a case of a significant increase in ATP, the water quality testing should be accompanied with methods for detection of specific bacteria (e.g. coliform bacteria, E. coli) in order to validate whether or not the drinking water poses a risk to public health. Hence, the best approach for monitoring microbial drinking water quality, in order to enhance water security and safety, is by combining rapid methods with methods targeted for specific bacterial detection.

Even though both Colilert-18 and the HPCs were better at detecting microbial ingress than the ATP assay, ATP definitely has potential as an early warning parameter because of its short response time (real-time). A fully automated in situ ATP analyser has been developed for measuring ATP in sea water (Fukuba et al., 2011). Further, a fully automated sensor prototype based on the ATP assay has been developed and investigated for monitoring ATP in drinking water (Vang, 2013). The ATP assay is able to deliver fast, reliable and quantitative results on the microbiological state of drinking water in a contamination 
incident, especially when the contaminant concentration is high, and it may also be applicable to detect pulse contaminations, i.e. a contamination of short duration with high ATP concentrations.

\section{Conclusions}

This study demonstrated that the ATP assay can provide fast and reliable results for detecting microbial ingress in drinking water, and thus it has potential as a parameter for continuous real-time monitoring of microbial drinking water quality. More specifically, the conclusions of this experimental study were:

- The ATP assay was able to detect up to a $10^{4}$ dilution of wastewater in drinking water.

- Quantifying microbial ATP did not significantly improve the ability of the ATP assay in detecting the wastewater contamination compared to measuring total ATP.

- Applying more sensitive reagents for the ATP analysis did not reduce the standard deviation of ATP measurements significantly for low concentrations of ATP, and consequently it did not contribute substantially to the ATP assay's ability to detect contaminations in drinking water.

- The ATP assay was able to detect a surface water dilution of $10^{2}$ to $10^{3}$ in drinking water.

- The ATP assay was better at differentiating between the wastewater and surface water contaminations and clean drinking water compared to TDC. HPCs and Colilert-18 exceeded the ATP assay with regard to detection of waste water and surface water in drinking water. ATP measurements are nevertheless advantageous with regard to response time, though they have to be supplemented with other more time-consuming methods for specific detection of bacteria.

- The ability of the ATP assay to detect a contaminant is influenced by both the microbial load of the specific contaminant as well as the background level of ATP of the specific drinking water. 
Acknowledgements: This work was supported by the Danish Council for Strategic Research and the SENSOWAQ (Sensors for Monitoring and Control of Water Quality) project. The UrbanWaterTech Research School is acknowledged. Thanks go to laboratory technicians Mona Refstrup and Sabrina Nedell for their valuable assistance in the laboratory. Torben Dolin and Lisbet Brusendorff are acknowledged for their assistance on graphics. Finally, thanks are extended to Lyngby-Taarbæk Forsyning $\mathrm{A} / \mathrm{S}$ and Nordvand $\mathrm{A} / \mathrm{S}$ for supplying us with drinking water, wastewater and surface water. 


\section{References}

Aoki, Y., Fukuba, T., Yamamoto, T., Fujii, T., 2008. Development of 'IISSA'-ATP system in deep sea environment. OCEANS 2008 - MTS/IEEE KOBE TECHNO-OCEAN, VOLS 1-3 Book Series: OCEANS-IEEE, 548-551.

Berney, M., Vital, M., Hülshoff, I., Weilenmann, H.-U., Egli, T., Hammes, F., 2008. Rapid, cultivationindependent assessment of microbial viability in drinking water. Water Research 42, 4010-4018.

Boe-Hansen, R., Albrechtsen, H.-J., Arvin, E., Jørgensen, C., 2002. Bulk water phase and biofilm growth in drinking water at low nutrient conditions. Water Research 36, 4477-4486.

Bushon, R.B., Likridopulos, C.A., Brady, A.M.G., 2009. Comparison of immunomagnetic separation/adenosine triphosphate rapid method to traditional culture-based method for E. coli and enterococci enumeration in waste water. Water Research 43, 4940-4946.

Camper, A.K., LeChevallier, M.W., Broadaway, S.C., McFeters, G.A., 1986. Bacteria associated with granular activated carbon particles in drinking water. Applied and Environmental Microbiology, 52, 3, 434-338.

Deininger, R.A., Lee, J., 2001. Rapid determination of bacteria in drinking water using an ATP assay. Field Analytical Chemistry and Technology, 5, 4, 185-189.

Delahaye, E., Welté, B., Levi, Y., Leblon, G., Montiel, A., 2003. An ATP-based method for monitoring the microbiological drinking water quality in a distribution network. Water Research 37, 3689-3696.

Denburg, J.L.; Lee, R.T.; McElroy, W.D., 1969. Substrate-binding properties of firefly luciferase - I. Luciferin-binding site, Arch. Biochem. Biophys. 134 , pp 381-394.

Deluca, M.; Wannlund, J.; McElroy, W.D., 1979. Factors affecting the kinetics of light emission from crude and purified firefly luciferase. Analytical Biochemistry, 95, pp. 194-198. 
Eydal, H.S., Pedersen, K., 2007. Use of an ATP assay to determine viable microbial biomass in Fennoscandian Shield groundwater from depths of 3-1000 m. Journal of Microbiological Methods 70, 363-373.

Frundzhyan, V., Ugarova, N., 2007. Bioluminescent assay of total bacterial contamination of drinking water. Luminescence, 22, 241-244.

Fukuba, T., Aoki, Y., Fukuzawa, N., Yamamoto, T., Kyo, M., Fijii, T., 2011. A microfluidic in situ analyser for ATP quantification in ocean environments. Lab on a Chip, 11, 3508-3515.

Reasoner, D.J., Geldreich, E.E., 1985. A new medium for the enumeration and subculture of bacteria from potable water. Applied and Environmental Microbiology, 49, 1-7.

Ghazali, M., McBean, E., Whalen, P., Journal, K., 2010. Supporting a drinking water contaminant warning system using the adenosine triphosphate test. Canadian Journal of Civil Engineering, 37, 1423-1431. Hammes, F., Berney, M., Wang, Y., Vital, M., Köster, O., Egli, T., 2008. Flow-cytometric total bacterial cell counts as a descriptive microbiological parameter for drinking water treatment processes. Water Research, 42, 269-277.

Hammes, F., Goldschmidt, F., Vital, M., Wang, Y., Egli, T., 2010. Measurement and interpretation of microbial adenosine tri-phosphate (ATP) in aquatic environments. Water Research 44 (13), 3915-3923. Hammes, F., Broger, T., Weilenmann, H.-U., Vital, M., Helbing, J., Bosshart, U., Huber, P., Odermatt, R. P., Sonnleitner, B., 2012. Development and Laboratory-Scale Testing of a Fully Automated Online Flow Cytometer for Drinking Water Analysis. Cytometry Part A, 81A, 508-516.

Hügler, M., Böckle, K., Eberhagen, I., Thelen, K., Beimfohr, C., Hambsch, B., 2012. Detection and quantification of E. coli and coliform bacteria in water samples with a new method based on fluorescence in situ hybridisation. In Kay, D., Fricker, C. (Eds.) Significance of faecal indicators in water: A global perspective. The Royal Society of Chemistry, UK, 123-130. 
Inkinen, J., Pitkänen, T., Miettinen, I.T., 2013. Suitability of optical, physical and chemical measurements for detection of changes in bacterial drinking water quality. International Journal of Environmental Research and Public Health, 10 (11), 5349-5363.

Inkinen, J., Kaunisto, T., Pursiainen, A., Miettinen, I.T., Kusnetsov, J., Riihinen, K., Keinänen- Toivola, M.M., 2014. Drinking water quality and formation of biofilms in an office building during its first year of operation, a full scale study. Water Research, 49, 83-91.

Johnson, G.D., Davidson, R.S., McNamee, K.C., Russel, G., Goodwin, D., 1982. Fading of Immunofluorescence during Microscopy: a Study of the Phenomenon and its Remedy. Journal of Immunological Methods, 55, 231-242.

Karl, D.M., 1980. Cellular nucleotide measurements and applications in microbial ecology. Microbiological Reviews, 44, 4, 739-796.

Lehtola, M.J., Juhna, T., Miettinen, I.T., Vartiainen, T., Martikainen, P.J., 2004. Formation of biofilms in drinking water distribution networks, a case study in two cities in Finland and Latvia. Journal of Industrial Microbiology \& Biotechnology, 31 (11), 389-494.

Liu, G., van der Mark, E.J., Verberk, J.Q.J.C., van Dijk, J.C., 2013a. Flow cytometry total cell counts: A field study assessing microbiological water quality and growth in unchlorinated drinking water distribution systems. BioMed Research International, Vol. 2013, Article ID 595872, p 1-10.

Liu, G., Ling, G.Q., Magic-Knezev, A., Liu, W.T., Verberk, J.Q.J.C., van Dijk, J.C., 2013b. Quantification and identification of particle-associated bacteria in unchlorinated drinking water from three treatments plants by cultivation-independent methods. Water Research, 47, 3523-3533.

Liu, G., Verberk, J.Q.J.C., van Dijk, J.C., 2013c. Bacteriology of drinking water distribution systems: an integral and multidimensional review. Applied Microbiology and Biotechnology, 97, 9265-9276.

Lutz, S., Weber, P., Focke, M., Faltin, B., Hoffmann, J., Muller, C., Mark, D., Roth, G., Munday, P., Armes, N., Piepenburg, O., Zengerle, R., von Stetten, F., 2010. Microfluidic lab-on-a-foil for 
nucleic acid analysis based on isothermal recombinase polymerase amplification (RPA). Lab. Chip 10 (7), 887e893.

Magic-Knezev, A., van der Kooij, D., 2004. Optimisation and significance of ATP analysis for measuring active biomass in granular activated carbon filters used in water treatment. Water Research, 38, 39713979.

Maki, J.S., LaCroix, S.J., Hopkins, B.S., Stanley, J.T., 1986. Recovery and Diversity of Heterotrophic Bacteria from Chlorinated Drinking Waters. Applied and Environmental Microbiology, 5 (5), 1047-1055. Marriott, N.J., Barnes, S.P., Smith, R.N., 1992. A comparative evaluation of three commercially available luminometers and two ATP reagent kits. International Biodeterioration \& Biodegradation, 30, 339-352. Nevel, S.V., Koetzsch, S., Weilenmann, H.-U., Boon, N., Hammes, F., 2013. Routine bacterial analysis with automated flow cytometry. Journal of Microbiological Methods, 94, 73-76.

Porter, K.G., Feig, Y.S., 1980. The use of DAPI for identifying and counting aquatic microflora. Limnology and Oceanography, 25(5), 943-948.

Rimhanen-Finne, R., Hanninen, M.L., Vuento, R., Laine, J., Jokiranta, T.S., Snellman, M., Pitkanen, T., Miettinen, I., Kuusi, M., 2010. Contaminated water caused the first outbreak of giardiasis in Finland, 2007: A descriptive study. Scandinavian Journal of Infectious Diseases, 42 (8), 613-619.

Siebel, E., Wang, Y., Egli, T., Hammes, F., 2008. Correlations between total cell concentration, total adenosine tri-phosphate concentration and heterotrophic plate counts during microbial monitoring of drinking water. Drinking Water Engineering Science, 1, 1-6.

Smeets, P.W.M.H., Medema, G.J., van Dijk, J.C, 2009. The Dutch secret: how to provide safe drinking water without chlorine in the Netherlands. Drinking Water Engineering Science, 2, 1-14.

Stanley, P.E., 1986. Extraction of adenosine triphosphate from microbial and somatic cells. Methods in Enzymology, 133, 14-22. 
Stedmon, C.A., Serdyńska-Sobecka, B., Boe-Hansen, R., Le Tallec, N., Waul, C.K., Arvin, E., 2011. A potential approach for monitoring drinking water quality from groundwater systems using organic matter fluorescence as an early warning for contamination events. Water Research 45, 6030-6038. van der Kooij, D., 1992. Assimilable organic carbon as an indicator of bacterial regrowth. American Water Works Association (AWWA), Vol. 84, No. 2, 57-65.

van der Kooij, 2003. Managing regrowth in drinking-water distribution systems. In: Emerging Issues in Water and Infectious Diseases Series. Heterotrophic plate counts and drinking-water safety: The significance of HPC's for water quality and human health, 199-232.

van der Kooij, D., Baggelaar, P.K., Veenendaal, H.R., Moulin, L., Corfitzen, C.B., Albrechtsen, H.-J., Holt, D.; Hambsch, B., 2006. Standardising the biomass production potential method for determining the enhancement of microbial growth by construction products in contact with drinking water - interlaboratory testing; EC Grant Agreement nbr. S12, 403889.

van der Wielen, P.W.J.J., van der Kooij, D., 2010. Effect of water composition, distance and season on the adenosine triphosphate concentration in unchlorinated drinking water in the Netherlands. Water Research, 44 (17), 4860-4867.

Vang, Ó.K., 2013. ATP measurements for monitoring microbial drinking water quality. DTU Environment, Technical University of Denmark, PhD Thesis.

Vang, Ó.K., Corfitzen, C.B., Spliid, H., Albrechtsen, H.-J., 2014a. Levels of microbial ATP and free ATP in non-chlorinated drinking water - assessing microbial drinking water quality with ATP measurements. In submission.

Vang, Ó.K., Corfitzen, C.B., Smith, C., Albrechtsen, H.-J., 2014b. Evaluation of reagents for the ATP assay for assessing microbial drinking water quality. In submission. 
Velten, S., Hammes, F., Boller, M., Egli, T. (2007) Rapid and direct estimation of active biomass on granular activated carbon through adenosine tri-phosphate (ATP) determination. Water Research, 41, 1973-1983.

Vestergaard LS, Olsen KE, Stensvold CR, Böttiger BE, Adelhardt M, Lisby M, Mørk L, Mølbak K., 2007. Outbreak of severe gastroenteritis with multiple aetiologies caused by contaminated drinking water in Denmark, January 2007. Eurosurveillance, 12(13), 3164.

Vital, M., Hammes, F., Magic-Knezev, A., Ross, P., Rietveld, L., Hammes, F., 2012. Flow cytometry and adenosine tri-phosphate analysis: Alternative possibilities to evaluate major bacteriological changes in drinking water treatment and distribution systems. Water Research, 46, 4665-4676. 